\title{
Influence of current density and duration of PET of AA2024 alloy on the rate and growth mechanisms of a coating's wear-resistant anticorrosive inner layer
}

\author{
A.G. Rakoch, ${ }^{1}{ }^{(D} *$ Z.V. Khabibullina, ${ }^{1}$ (D) O.V. Volkova, ${ }^{1}$ (D) A.V. Borko, ${ }^{1}$ \\ Tran Van Tuan, ${ }^{1}$ ID I. V. Suminov ${ }^{2} \mathbb{D}$ and S.V. Zhukov ${ }^{2} \mathbb{D}$ \\ ${ }^{1}$ Department of Metal Protection and Surface Treatment, National University of Science \\ and Technology "MISiS”, Leninsky pr. 4, 119049 Moscow, Russian Federation \\ ${ }^{2}$ Moscow State University of Technology "STANKIN", Vadkovskiy per. 1, 127055 Moscow, \\ Russian Federation \\ *E-mail: rakoch@mail.ru
}

\begin{abstract}
In this study the growth mechanisms of two-layered hard anticorrosive PE coatings on AA2024 alloy are given. During PET the following phenomena take place: i) The formation of a coating's outer layer mainly occurs as a result of the melted aluminum oxide transportation onto a coating's surface, accompanied with the influence of a large amount of the gas-vapor phase on it, which happens right after the microdischarges extinction in coating's transverse pores. ii) The growth of coating's inner layers occurs via two mechanisms. The first one is based on the formation of melted aluminum oxide without its transportation onto a coating's surface. The ignition of anodic plasma microdischarges under the coating's outer layer results in the sealing of coating's inner layer's pores and the adjacent ones that are located in the outer layer. This process takes place during the ignition of microdischarges under the anodic "semiperiod" until the voltage reaches its maximum value. The second mechanism is based on the convective and diffusive transfer of aluminum and oxygen ions through the melted parts of the coating's inner layers which are adjacent to the powerful microdischarges. These microdischarges appear in the coating's transverse pores generally when the voltage reaches its peak values. The second mechanism of the PE coatings' growth is prevalent when the pores amount in the inner layer decreases significantly. iii) The rapid growth of a coatings' average thickness from 50 to $80 \mu \mathrm{m}$ with or without a slight average dimensional one-side change of the samples might be caused by the consumption of aluminum for both the growth of PE coating and the sealing of the voids and transverse pores which are particularly located in the inner layers. iv) The significant raise of a current density which is applied for processing PE treatment of AA2024 alloy, results only in the increase of the coatings' growth rate. There is no impact on the growth of coatings' thickness which occurs via different mechanisms. It was demonstrated that to synthesize a wear-resistant anticorrosive inner layer, the PE processing under the alternating current densities of 15$45 \mathrm{~A} / \mathrm{dm}^{2}$ should be conducted till the coating's thickness reaches more than $80 \mu \mathrm{m}$.
\end{abstract}

Received: September 24, 2021. Published: November 23, 2021

doi: $\underline{10.17675 / 2305-6894-2021-10-4-15}$

Keywords: aluminum alloy, plasma electrolytic treatment, coating 's growth mechanism. 


\section{Introduction}

Aluminum alloys are widely used in different industrial fields. However, low corrosion and wear resistances of wrought and casting aluminum alloys significantly limit their broad use, thus, protective coatings are applied on constructions and items made of them [1-6]. The most popular method of their protection is anodizing [1,7,8]. The anodizing of these alloys is made after a multistage pre-treatment of their surfaces. It consists of degreasing, etching, defectation and washing in hot and cool water after each stage [1,7]. Moreover, paints, enamels or any other top coatings are often applied on the anodic coatings as inhibitors in order to increase their corrosion resistances $[1,3,7]$.

Nowadays researchers are focused on finding a replacement for such multistage surface treatments of aluminum alloys e.g. by plasma electrolytic treatment (PET) which is followed by water rinsing or exposure in a slightly acidified aqueous solution in case if the PET was conducted in alkali electrolytes [8-11]. Obviously, it is a much easier two-stage process.

During PET processing, generally two-layered coatings grow [9,11-17]. The formation of a passive layer on a metallic bottom of the transverse pores takes place after the water rinsing and drying of PE coated aluminum alloys. Thereby, one can find some studies about the growth of three-layered PE coatings [8, 10].

The coatings' formation mainly occurs as a result of the aluminum oxidation when PET of aluminum alloys is conducted in alkali aqueous solutions that contain up to $10 \mathrm{~g} / \mathrm{L}$ of anions or polyanions like $\mathrm{SiO}_{3}^{2-}, n\left[\mathrm{Si}_{x} \mathrm{O}_{y}\right]^{m-}, \mathrm{Al}(\mathrm{OH})_{4}^{-}$. However, these anions or polyanions being electrolytic cathodes participate in the ignition of plasma microdischarges and raise of energy releasing in them [8].

Only the inner (working [10]) layers of PE coatings with the pores that are sealed with a passive layer, provide high anticorrosion, wear-resistance properties and adhesion to a metal substrate [8-14]. The growth of outer highly porous layers results only in the dimensional one side change of samples and items made of aluminum alloys. In most of the cases, the outer layers are polished out, and this is an additional faulty operation. Therefore, it is needed to develop PET process parameters, which will allow to synthesize coatings on aluminum alloys with a thin outer layer.

It was found that there are four stages of the coatings' thickness growth with different rates of the one-side dimensional change of samples during PET processing of wrought aluminum alloys [9]. However, the research did not establish the following aspects: i) a ratio of inner and outer layers' growth rates in these time intervals; ii) influence of the widely applied alternating current densities for the PET processing of aluminum alloys on these ratios; iii) main mechanisms of the coatings' inner layer's formation during different stages of PET processes.

The lack of knowledge about the moment when the outer layer's growth rate $\left(V_{h \text { (out) }}\right)$ starts to exceed significantly the rate of the inner one $\left(V_{h(\text { in })}\right)$ during the application of different current densities or various treatment durations may result in the insufficient energy consumptions and the degradation of environmental situation at a working area. 
Moreover, the knowledge about the influence of PET processing duration and applied alternative current density on properties of a PE coatings' inner layer will allow to upgrade the previous mechanisms of PET processing, given in [18-23], and develop protective coatings on aluminum alloys.

Thus, the aims of the present study are:

1) To find out the influence of a PET duration with the application of various current densities on main properties of a PE coatings' inner layer and $V_{h \text { (in) }} / V_{h \text { (out) }}$ ratio;

2) To upgrade the growth mechanism of the two-layered PE coatings on AA2024 alloy.

\section{Experimental}

\section{Preparation of PE coatings}

PET processes were carried out in a galvanostatic mode under the applied current densities of $15 ; 30 ; 45 \mathrm{~A} / \mathrm{dm}^{2}$ by use of a capacity-based equipment, previously described in detail [24]. Currents corresponding to the given densities were stabilized according to their average rectified value.

Cylindrical samples of AA2024 alloy (wt.\%: $3.9 \mathrm{Cu}, 0.6 \mathrm{Mn}, 1.6 \mathrm{Mg}, 0.5 \mathrm{Si}, 0.5 \mathrm{Fe}$, $0.1 \mathrm{Cr}, 0.25 \mathrm{Zn}, 0.15 \mathrm{Ti}, \mathrm{Al}$ - balance) with a diameter of $20 \mathrm{~mm}$ and length of $5.5 \mathrm{~mm}$ were used in frame of this research. The following chemicals were used for preparation of PET electrolyte, $\mathrm{g} / \mathrm{L}$ ( $\mathrm{pH} \sim 12.4): 2 \mathrm{NaOH}$ and 7 technical water glass (TWG, $\mathrm{Na}_{2} \mathrm{O} \cdot 2.9 \mathrm{SiO}_{2} \cdot 18$ $\mathrm{H}_{2} \mathrm{O}$ ). A total volume of the electrolyte was constantly adjusted to $5 \mathrm{~L}$. Every $8 \mathrm{~h}$ of PET processing under all the applied current densities the electrolyte was replaced with the new one. The same replacement age of the electrolyte for all current densities is caused by the low consumption of ions and polyanions of the aqueous solution: the growth of the PE coatings mainly occurs via the oxidation of a metal substrate [8-13].

The $\mathrm{pH}$ of the electrolyte was measured using a "pH 211" $\mathrm{pH}$-meter, its value was 12.4.

\section{Coating characterization}

Cross-section morphology of the PE coatings were examined by scanning electron microscopy using a Tescan VEGA3 SB instrument and elemental composition of the coatings were studied at different places using an X-Act energy dispersive X-ray spectrometer.

Thicknesses of the coatings were measured at randomly selected locations using a Dualscope FNP10 Coating Thickness Gauge and the average values were calculated. The device was calibrated using an uncoated substrate material. A MEGEON 80800 digital micrometer was used to estimate the samples' one-side dimensional change. A sample's each dimension was measured before and after every five-minute of PET processing by use of this device. Then, having aimed to calculate the one-side dimensional change, the obtained results were divided by two. The data of the coatings' thickness and samples' one-side 
dimensional change, given in this study, are taken from a set of experimental data of at least ten measurements.

The estimation of the inner layer's average thickness from the SEM micrographs of the PE coatings' cross section morphology was conducted by use of the ImageJ software. The output result of the inner layer's thickness is a value of the area of the coating's microregions divided by the length of these regions. At least 3 micro-areas were selected for each sample and the average values are given in this study. The average thickness of its outer layer was estimated by subtracting the average thickness of the inner layer from the average thickness of the PE coating.

\section{High-speed video shooting of the microdischarges}

The monochrome high-speed video shooting of the plasma microdischarges was conducted using a Photron fastcam SA5 camera. A speed of shooting was 20000 frames per second.

\section{Electrochemical measurements}

Electrochemical measurements were performed using an ICP-Pro 3A potentiostat. Threeelectrode configurations, with an $\mathrm{Ag} / \mathrm{AgCl}$ reference electrode and a platinum-coated titanium or a platinum wire counter electrodes were used. The samples without and with PE coatings were operated as a working electrode while being exposed to $3 \mathrm{wt}$. $\% \mathrm{NaCl}$ solution. Anodic polarization was performed in a potentiodynamic mode with a potential scan rate of $0.5 \mathrm{mV} / \mathrm{s}$. Initially the open circuit potentials (OCP) were settled during $45 \mathrm{~min}$ for the uncoated and coated samples, respectively, and then the polarization curves were recorded from a cathodic region to the anodic one, starting from values of $-200 \mathrm{mV}$ relative to OCP.

\section{Adhesion and microhardness of the PE coating layer}

Pull-off adhesion method to determine adhesion between the coating's outer and inner layers an Elcometer 510 was used with a pull rate of $0.1 \mathrm{MPa} / \mathrm{sec}$. Prior to the measurements, a $10 \mathrm{~mm}$ dolly was glued to samples's surface using a two-component adhesive epoxy glue Araldite Standard 2K. The transverse adhesion of this glue is more than $52 \mathrm{MPa}$.

A Buehler Micromet 5101 tester with a Vickers diamond indenter was used to evaluate microhardness of the inner (working) layer of the PE coatings under a load of $100 \mathrm{~g}$, applied for $10 \mathrm{~s}$.

\section{Results and Discussion}

Kinetics of PE coatings thickness growth and samples one-side dimensional evolution on AA2024 alloy

It can be seen that the increase of the applied current density for 2, 3 times results in almost the same ratio of the average PE coatings' growth rates on AA2024 alloy (Table 1). It might be based on a fact that the amount of energy that is consumed for the formation of coatings with similar thickness is almost the same regardless of a value of the applied current density. 
Prior to the ignition of plasma microdischarges, an anodic component of the alternating current is consumed for the anodizing, the evolution of oxygen, Joule heat and the minor dissolution of the alloy in pores of the growing layer. During the ignition of plasma microdischarges the energy is mainly consumed for the formation of oxides and Joule heat. The growth of PE coatings takes place during anodic "semiperiod" [8-10]. The raise of the anodic voltage is limited by the breakdowns of a gas-vapor phase, which is formed in the coating's transverse pores during PET processing. A size of pores' cross sections, existence of intermetallics and different inclusions at their bottom result in the diverse electrolyte resistance, located in the pores, and the different rates of the reactions. As a consequence, a gas-vapor phase of various heights which is not a function of the applied current density is formed. The raise of a current density leads only to the more rapid reaching of the gasvapor's breakdown voltage. Therefore, the anodic voltage during PET of aluminum alloy almost does not depend on a value of the applied current density (Figure 1). The time needed to synthesize the PE coatings with a same thickness decreases almost linearly with a value of the applied current density (Table 1). Therefore, one can conclude that the amount of energy consumed for the growth of PE coatings of a similar thickness does not depend on a value of the applied current density.

Table 1. Average ratios of the applied current densities, treatment's durations and the coatings' thickness growth.

\begin{tabular}{cccccc}
\hline $\boldsymbol{i}_{\mathbf{3 0}} / \boldsymbol{i}_{\mathbf{1 5}}$ & $\boldsymbol{i}_{\mathbf{4 5}} / \boldsymbol{i}_{\mathbf{3 0}}$ & $\boldsymbol{\tau}_{\mathbf{1 5}} / \boldsymbol{\tau}_{\mathbf{3 0}}$ & $\boldsymbol{\tau}_{\mathbf{3 0}} / \boldsymbol{\tau}_{\mathbf{4 5}}$ & $\boldsymbol{V}_{\mathbf{3 0}} / \boldsymbol{V}_{\mathbf{1 5}}$ & $\boldsymbol{V}_{\mathbf{4 5}} / \boldsymbol{V}_{\mathbf{3 0}}$ \\
\hline 2.0 & 1.5 & 1.94 & 1.46 & 1.94 & 1.46 \\
\hline
\end{tabular}

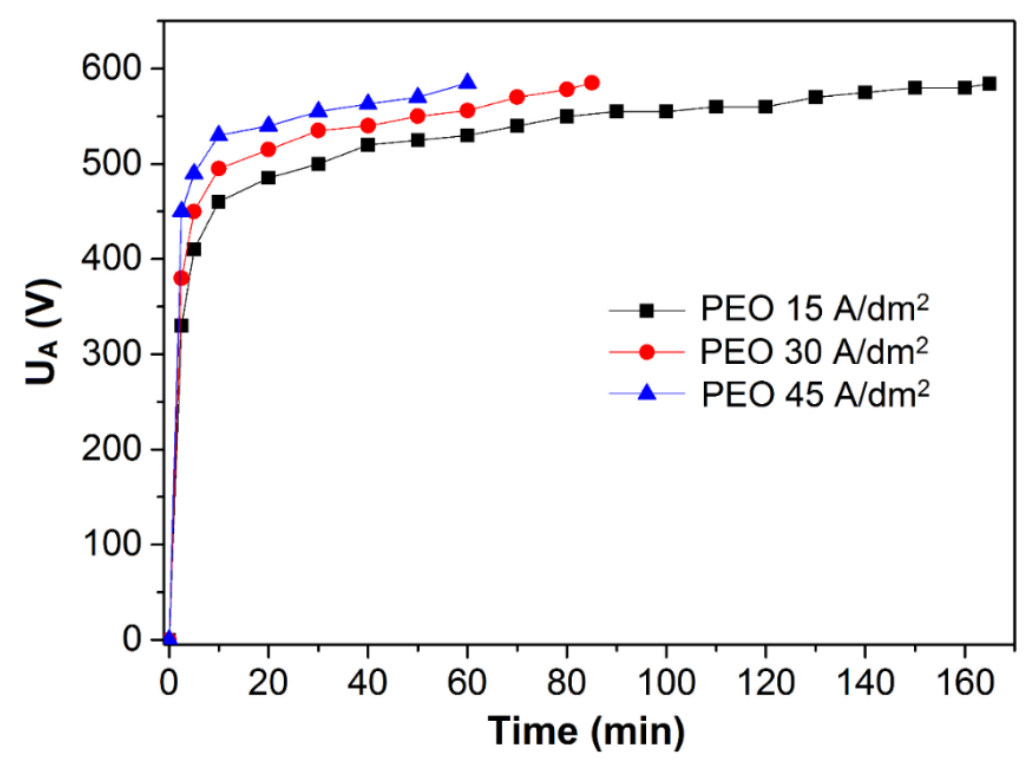

Figure 1. The evolution of anodic voltage as a function of time during PET of AA2024 alloy in the aqueous solution, containing g/L: $2 \mathrm{NaOH}, 7 \mathrm{TWG}$ under the various applied current densities. 
It can be seen that there are four stages with different tendencies of average one-side dimensional evolution of the samples for the current densities that are applied for PET processing in this study (Figure 2). These data confirm the results established in [9]. Thus, during the first stage of PET under all the applied current densities, the one-side dimensional change of the samples takes place in accordance with the average growth of a coating's thickness. During the second stage, the average growth rate of PE coatings' thickness exceeds the average rate of the samples' one-side dimensional change. During the third stage, the average growth rates of PE coatings, synthesized under the current densities of 15; $30 ; 45 \mathrm{~A} / \mathrm{dm}^{2}$, are $0.8 ; 1.5 ; 2.3 \mu \mathrm{m} / \mathrm{min}$, respectively. However, at this stage, the samples' one-side dimension changes slightly or stays constant (Figure 2). Moreover, during the third interval of PET processing of AA2024 alloy, the samples' one-side dimension stays constant or changes slightly until the coating's average thickness reaches the value of $80 \pm 2 \mu \mathrm{m}$ and then the fourth stage begins. During the fourth stage, the samples' one-side dimension raises with the thickness of PE coatings (Figure 2).
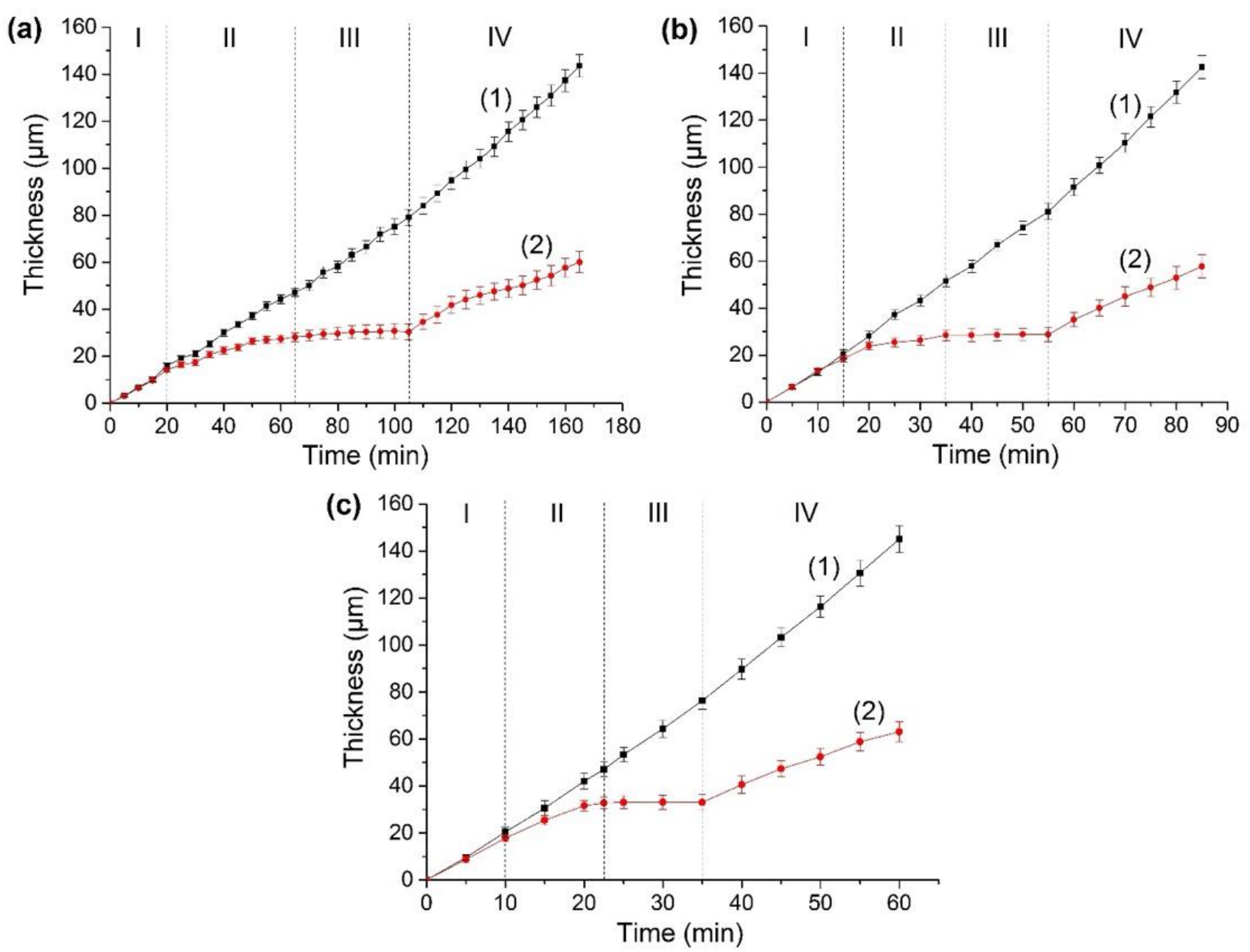

Figure 2. The kinetics of coatings' thickness' growth (1) and samples' one-side dimensional evolution (2) during PET of AA2024 alloy in the aqueous solution, containing g/L: $2 \mathrm{NaOH}$, 7 TWF, under the applied current densities of A/dm²: 15 (a); 30 (b); 45 (c). 
The obtained results indicate that the growth mechanism of the two-layered [20] PE coatings on AA2024 alloy is complicated.

For a deeper understanding of the features of the samples' one-side dimensional change, during PET processing of AA2024 alloy, a structure and composition of the coatings that are synthesized at the end of each interval (Figure 2) should be studied.

Structure and composition of the coatings
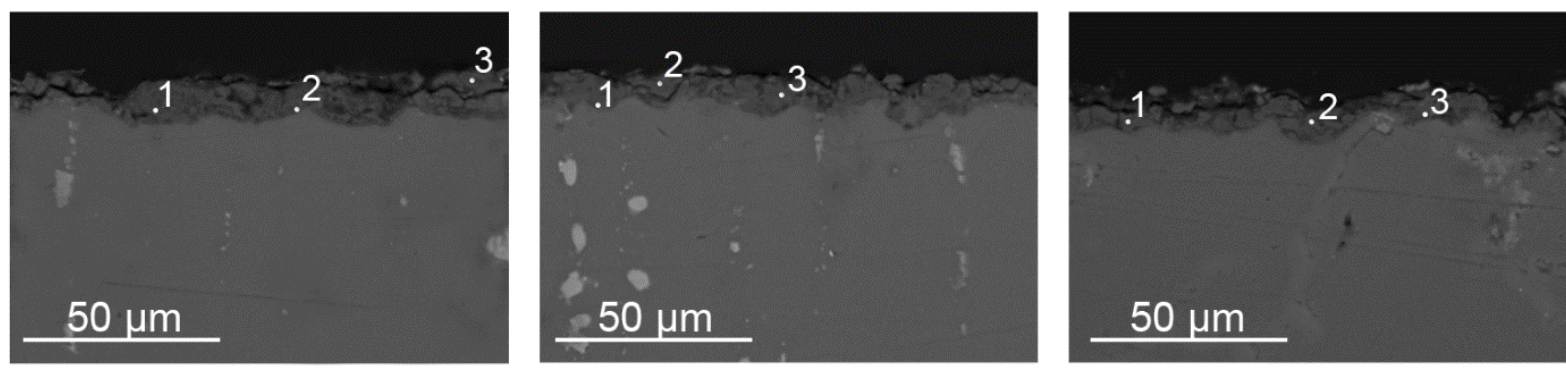

$10 \mu \mathrm{m}$
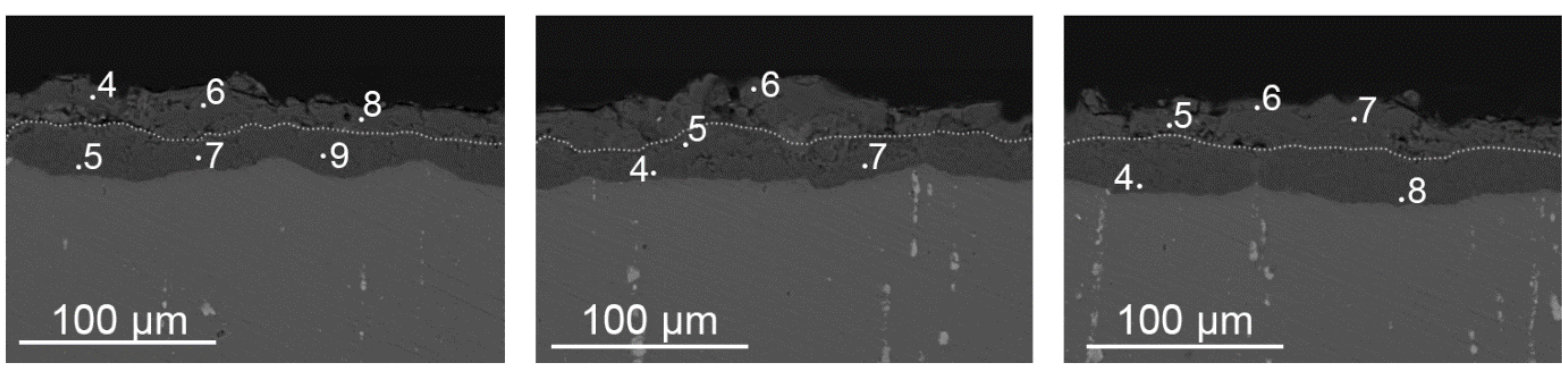

$50 \mu \mathrm{m}$
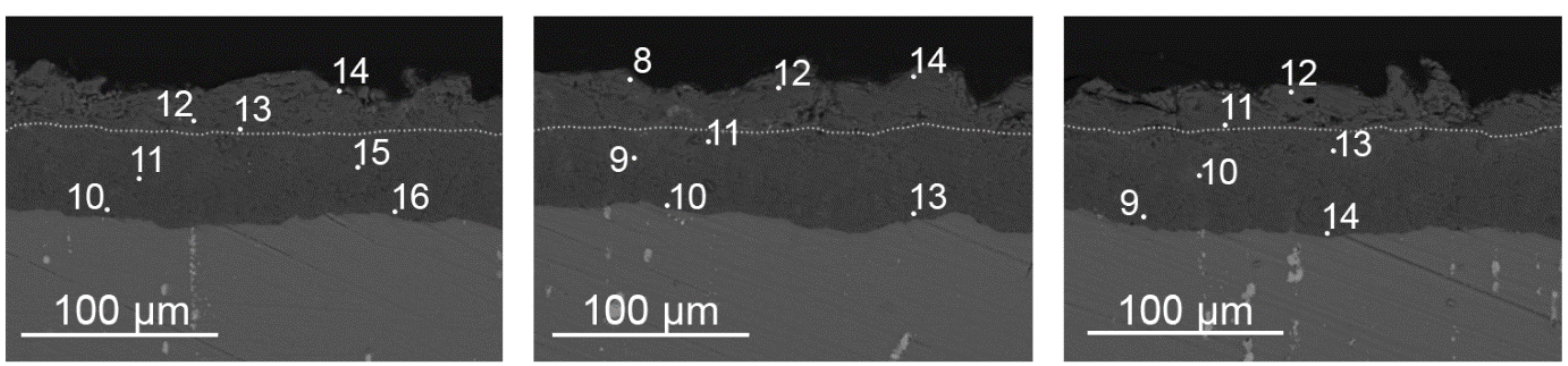

$80 \mu \mathrm{m}$

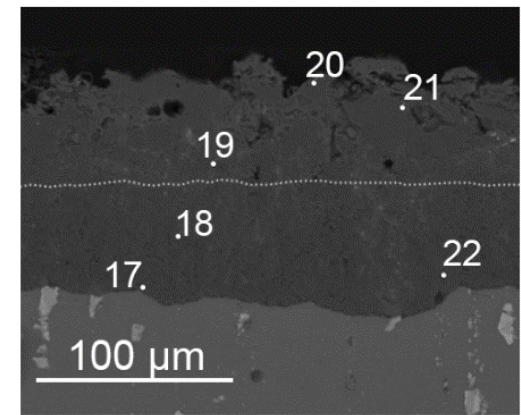

(a)

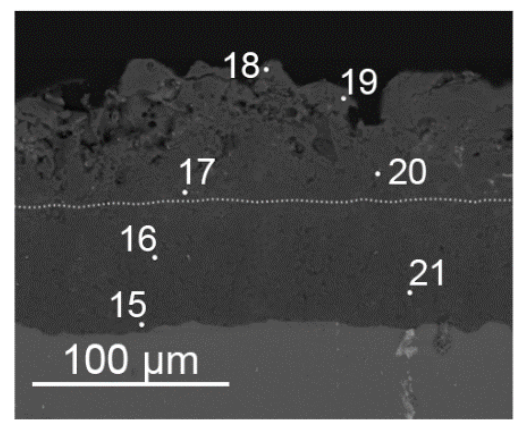

(b)

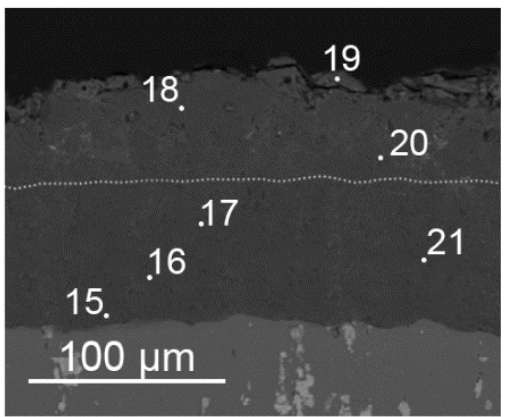

(c)

Figure 3. SEM micrographs of cross section morphology of the PE coatings synthesized on AA2024 alloy in the aqueous solution, containing g/L: $2 \mathrm{NaOH}, 7 \mathrm{TWF}$, under the applied current densities of $\mathrm{A} / \mathrm{dm}^{2}: 15$ (a); 30 (b); 45 (c). 
Table 2. Range of elements content in the PE coatings, obtained on AA2024 alloy (locations of analysis according to Figure 3 ).

\begin{tabular}{|c|c|c|c|c|c|c|c|}
\hline $\begin{array}{l}\text { Current } \\
\text { density, } \\
\text { A/dm }\end{array}$ & Points & Al & $\mathbf{O}$ & $\mathbf{S i}$ & $\mathrm{Cu}$ & Mg & Mn \\
\hline \multirow{7}{*}{15} & $1 ; 2 ; 3$ & $41.7-49.2$ & $47.7-55.1$ & $1.1-2.6$ & $0.2-0.4$ & $0.1-0.7$ & $0.2-0.3$ \\
\hline & $4 ; 6 ; 8$ & $47.7-50.4$ & $48.0-48.3$ & $1-3.3$ & $0-0.7$ & $0.3-0.4$ & $0-0.2$ \\
\hline & $5 ; 7 ; 9$ & $44.5-51.4$ & $48.2-53.7$ & $0-1.2$ & $0.1-0.6$ & $0.2-0.6$ & $0.1-0.3$ \\
\hline & $10 ; 11 ; 15 ; 16$ & $48.7-51.3$ & $45.6-48.9$ & $0-1.8$ & $0.5-2.1$ & $0.6-1.3$ & $0-0.2$ \\
\hline & $12 ; 13 ; 14$ & $47-51.2$ & $43.2-50.3$ & $1.2-3.2$ & $1-1.9$ & $0.4-0.7$ & $0.1-0.3$ \\
\hline & $17 ; 18 ; 19 ; 22$ & $49.5-52.9$ & $44.5-48.8$ & $0.2-1.4$ & $0.6-1.5$ & $0.5-0.7$ & $0-0.4$ \\
\hline & $20 ; 21$ & $37.1-45.8$ & $38.1-40.2$ & $11.4-22.7$ & $1.6-1.8$ & $0.4-0.7$ & 0.1 \\
\hline \multirow{7}{*}{30} & $1 ; 2 ; 3$ & $45.7-49.7$ & $47.2-52.4$ & $0.9-2.0$ & $0-0.3$ & $0.1-0.7$ & $0.1-0.3$ \\
\hline & $4 ; 5 ; 7$ & $48.7-49.9$ & $48.4-48.8$ & $0-0.4$ & $0.8-1.9$ & $0.3-0.4$ & $0.2-0.3$ \\
\hline & 6 & 47.3 & 51.5 & 1.0 & - & 0.2 & - \\
\hline & $8 ; 12 ; 14$ & $45.6-47.1$ & $48.5-49.0$ & $2.2-3.3$ & $0.9-1.9$ & $0.3-0.5$ & $0.1-0.2$ \\
\hline & $9 ; 10 ; 11 ; 13$ & $49.7-51.2$ & $47.5-48.4$ & $0-0.3$ & $0.7-1.7$ & $0.1-0.7$ & $0-0.2$ \\
\hline & $15 ; 16 ; 21$ & $49.9-52.1$ & $46.0-47.3$ & $0-0.6$ & $0.5-2.5$ & $0.4-1.0$ & $0.0-0.3$ \\
\hline & $17 ; 18 ; 19 ; 20$ & $28.6-44.8$ & $42.2-48.5$ & $11.5-22.3$ & $0.4-1.7$ & $0.1-0.5$ & $0.1-0.2$ \\
\hline \multirow{7}{*}{45} & $1 ; 2 ; 3$ & $46.7-49.8$ & $48.7-52.1$ & $0.4-1.6$ & $0.2-0.4$ & $0.1-0.2$ & $0.1-0.3$ \\
\hline & $4 ; 8$ & $50.9-51.3$ & $47.5-47.9$ & $0.2-0.3$ & $0.3-0.7$ & $0.2-0.3$ & $0.1-0.2$ \\
\hline & $5 ; 6 ; 7$ & $47.5-49.6$ & $47.7-49.5$ & $1.4-2.7$ & $0.1-1.0$ & $0.2-0.5$ & $0-0.3$ \\
\hline & $9 ; 10 ; 13 ; 14$ & $48.2-50.1$ & $47.3-50.0$ & $0-0.7$ & $0.8-1.4$ & $0.3-0.4$ & $0-0.2$ \\
\hline & $11 ; 12$ & $47.1-47.4$ & $47.3-48.7$ & $2.2-3.6$ & $1.4-1.5$ & $0.2-0.3$ & $0.1-0.2$ \\
\hline & $15 ; 16 ; 17 ; 21$ & $45.9-50.7$ & $45.9-49.1$ & $0.2-3.2$ & $1.3-2.6$ & $0.3-0.7$ & $0-0.2$ \\
\hline & $18 ; 19 ; 20$ & $30.4-46.8$ & $43.2-48.5$ & $8.9-17.4$ & $0.8-3.4$ & $0.1-0.4$ & $0-0.2$ \\
\hline
\end{tabular}

It can be seen that at the end of the first stage, highly porous coatings are formed under the current densities applied in this study (Figure 3). During the second stage, more dense inner layers start to grow under the initial outer ones. The latter leads to the difference in average rates of the coatings' thickness' growth and the samples' one-side dimensional change. Thus, during the second stage, the average growth rates of the coatings' thickness are $0.70 ; 1.55 ; 2.20 \mu \mathrm{m} / \mathrm{min}$ and the average rates of the samples' one-side dimensional evolution are $0.3 ; 0.5 ; 1.0 \mu \mathrm{m} / \mathrm{min}$, for the PE coatings, synthesized under the current densities of $15 ; 30$ and $45 \mathrm{~A} / \mathrm{dm}^{2}$, respectively (Figure 2). During the third stage, the samples' one-side dimension stays constant or changes slightly, while the average rates of 
the coatings' thickness' growth still have values similar to the ones at the second stage (Figure 2). During this interval the formation of the thick inner layer takes place (Figure 3). Despite the fact that the samples' one-side dimensional change occurs during the fourth stage, the final average thickness of an inner layer of $50 \pm 3.5 \mu \mathrm{m}$ is almost the same as the one obtained at the completion of the third stage for the all applied current densities.

$\mathrm{PE}$ coatings mainly consist of different phases of aluminum oxide, in most cases $\gamma$ - and $\alpha-\mathrm{Al}_{2} \mathrm{O}_{3}$ [8-18]. This is also confirmed by the elemental composition of the coatings (Table 2).

\section{A mechanism of the two-layered PE coatings formation in the alkali silicate electrolyte}

Having taken into account the mechanisms of the PE coatings' growth on AA2024 alloy at different stages of PET processing, given in [18-24], and the abovementioned experimental data, a mechanism of the two-layered PE coatings formation was developed and proposed in this study.

It was previously established, that in alkali silicate electrolytes the anodizing of aluminum alloys takes place prior to the appearance of the plasma microdischarges. This leads to the formation of a porous layer [9, 10, 18, 20-25]. A current density flowing through a metallic bottom of the transverse pores exceeds at least by one order of magnitude the nominally applied current value, which is calculated with respect to the sample's entire area $[8,20]$. The emission of anodic oxygen and vapor takes place in the pores, thus, resulting in the formation of a dielectric layer on the surface. The latter leads to a significant and rapid increase of the anodic voltage up to the breakdown voltage of a vapor-gas phase, leading to the ignition of anodic plasma microdischarges [14, 26-33].

Based on X-ray microanalysis data (Table 2), during the first stage of PET processing of AA2024 alloy, mainly the oxidation of a metal substrate takes place. It can be seen that high concentrations of aluminum and oxygen are found in the coatings that are grown at the end of the first stage. Moreover, a small amount of $\mathrm{Si}$ is also detected in this layer. Probably, it exists in a state of silicon dioxide, which is formed as a result of $n\left[\mathrm{Si}_{x} \mathrm{O}_{y}\right]^{m-}$ polyanions' electrolysis $[34,35]$ and the thermochemical treatment of the electrolyte, surrounding a working electrode [10]. These processes do not occur intensively due to the large closure of the working electrode's surface by a gas-vapor phase. The latter takes place as a result of the ignition of numerous amount of anodic plasma microdischarges during the first stage of PET [9].

During the second stage at the beginning of the anodic "semiperiod" [8,9], a large number of easily distinguishable micro-discharges are ignited as a result of the electrical breakdown of a gas-vapor phase, which is formed in the pores of the PE coatings. These small microdischarges keep appearing on the working electrode's surface until the anodic voltage reaches its peak. The sealing of the pores mainly with aluminum oxide at the coating bottom leads to the early formation of an inner layer. Further continuation of the PET processing results in the electrical breakdown of a gas-vapor phase, a height of which does 
not exceed the thickness of a coating's inner layer, in the pores of this layer by the time when the anodic voltage reaches its maximum values (Figure 4).
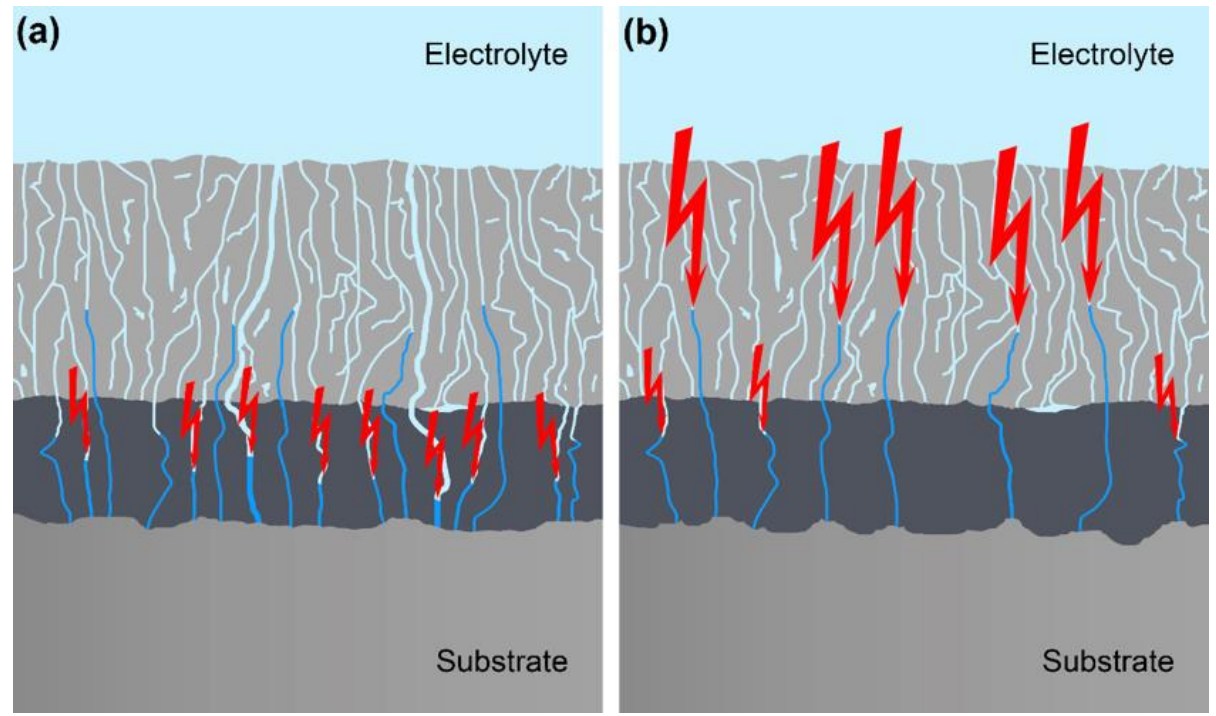

Figure 4. A mechanism of the plasma microdischarges ignition: (a) under the coatings' outer layer; (b) under the coatings' outer layer and in the transverse pores.

During extinction of the plasma the forming melted oxides seal the inner layer's pores and the adjacent ones that are located in the outer layer. When the anodic voltage reaches its peak, it can be seen that an amount of the small microdischarges decreases and the single bright powerful plasma microdischarges appear (Figures 4,5).
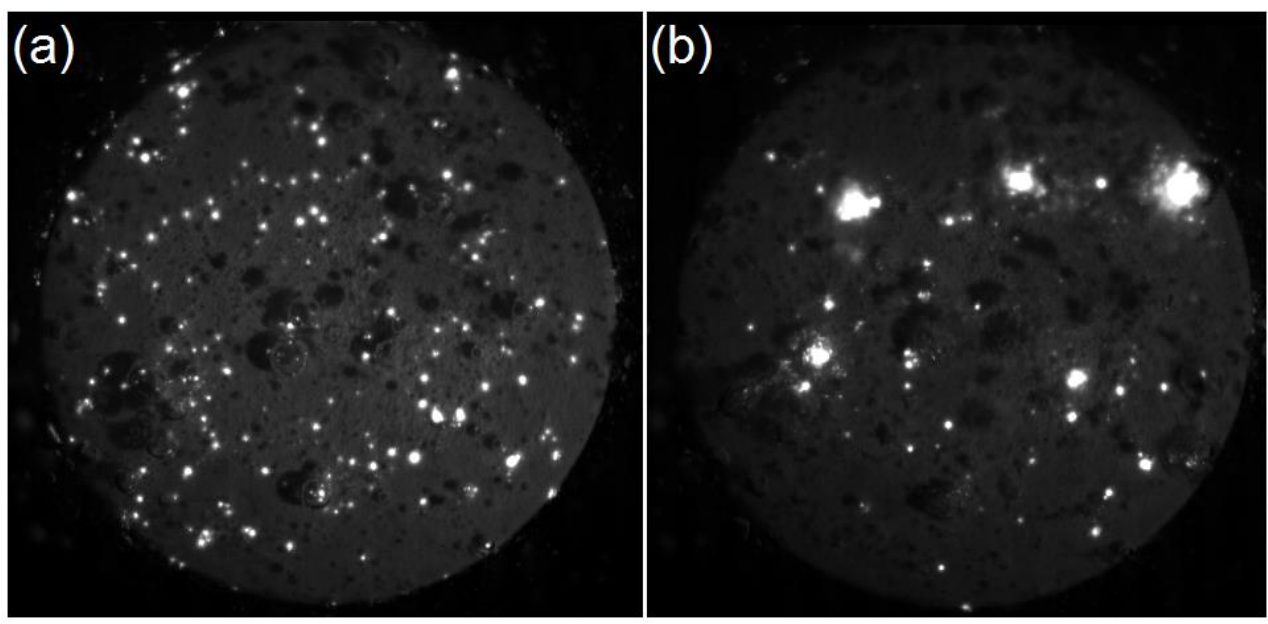

Figure 5. Appearance of the microdischarges during the second and third stages of PET in the anodic "semiperiod" intervals of: $2-5$ (a); 6-8 (b) msec. Shutter time is up to $50 \mathrm{sec}$.

The ignition of the large brightly-burning microdischarges leads to the transportation of the melted materials on the PE coatings' surface. This results in the formation of the coatings' outer layer with the presence of crater-shaped microdefects on its surface $[8,36]$. Moreover, these powerful microdischarges are accompanied by a release of high energy and, 
thus, play a meaningful role in the formation of the coatings' inner layer. The area of the alternate melted regions of the coatings' inner layer and the metal substrate, adjacent to the microdischarges, increases with the raise of energy, releasing in these plasma microdischarges. The local melting of the inner layer's regions is also confirmed by the formation of the dendritic defects in the PE coatings, grown on the aluminum alloy [12]. A more rapid filling of the voids with aluminum oxide results in the difference of the coatings' thickness' growth rate and the one-side dimensional change of the samples (Figure 2). The intensive compaction of the coatings' inner layer takes place during the third stage of the PET of AA2024 alloy. The high rate of the inner layer's thickness' growth is caused by the increase of the area of the inner layer's melted regions during the anodic "semiperiod". The formation of the coatings' inner layers in these regions occurs via the mechanisms of convection and diffusion (Figure 6). Moreover, the rates of the coatings' inner layer's growth significantly exceed the ones of the one-side dimensional change during PET processing under all the applied current densities. The complementary consumption of aluminum for the formation of its oxides in the pores and the compaction of the coatings' inner layer leads to a significant drop of the rates ratio "samples" one-side dimensional change/coatings" thickness' growth'. Thus, during the third stage this ratio tends to zero. At the end of this stage a value of $V_{h \text { (in) }} / V_{h \text { (out) }}$ ratio is not less than 2.5 (Table 3 ).

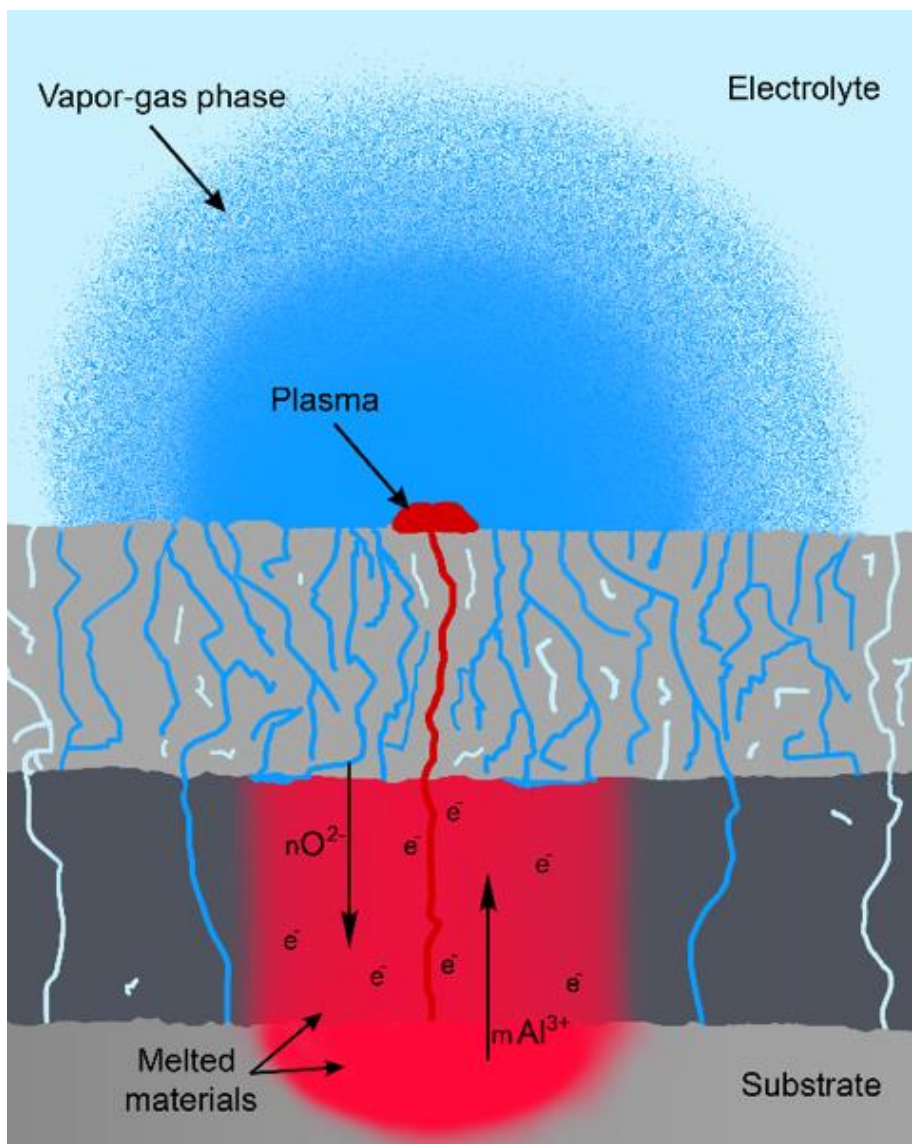

Figure 6. A schema of the convective and diffusive transfer of reactants through the melted parts of the PE coatings' inner layer during its growth. 
Table 3. Average rates of the PE coatings' inner and outer layers formation, their ratio at the end of each stage (II-IV) for all the applied current densities.

\begin{tabular}{|c|c|c|c|c|}
\hline $\begin{array}{c}\text { Current density, } \\
\mathbf{A} / \mathbf{d m}^{2}\end{array}$ & Stage & $V_{h(\mathrm{in})}, \mu \mathrm{m} / \mathrm{min}$ & $V_{h(\text { out })}, \mu \mathrm{m} / \mathrm{min}$ & $V_{h(\text { in })} / V_{h(\text { out })}$ \\
\hline \multirow{3}{*}{15} & II & 0.50 & 0.20 & 2.5 \\
\hline & III & 0.65 & 0.15 & 4.3 \\
\hline & IV & 0.25 & 0.85 & 0.3 \\
\hline \multirow{3}{*}{30} & II & 1.10 & 0.45 & 2.4 \\
\hline & III & 1.15 & 0.35 & 3.3 \\
\hline & IV & 0.50 & 1.55 & 0.3 \\
\hline \multirow{3}{*}{45} & II & 1.40 & 0.80 & 1.8 \\
\hline & III & 1.65 & 0.65 & 2.5 \\
\hline & IV & 0.70 & 2.00 & 0.4 \\
\hline
\end{tabular}

The melting of the regions of the coatings' outer layer does not occur because the energy releasing in the microdischarges mainly leads to the transformation of the aqueous solution, located in the pores adjacent to the microdischarges, to the vaporous state (Figure 6). Probably, the intensive release of a large amount of the formed gas is a main reason for the formation of many pores in the coatings' outer layer (Figure 3 ). Therefore, a structure of the outer layer's surface is unexpectedly uniform.

During the fourth stage of PET processing, a drop of the inner layer's growth is associated with the energy consumption mainly for the growth of the coatings' outer layer. With further continuation of PET a surface density of the plasma microdischarges during the anodic "semiperiod" decreases. As a consequence, the area of a working electrode covered with a gas-vapor phase reduces. During the fourth stage, in contrast to the first three ones of PET processing, the intensive electrolysis of the polyanions and thermochemical treatment of the electrolyte, which is located close and above the plasma microdischarges, take place. The concentration of compounds containing $\mathrm{Si}$ in the coatings' outer layer considerably increases (Table 2). As a consequence, during the fourth stage, there is a rapid growth of the PE coatings' outer layer (Table 3 ).

It should be noted that a slight change of the inner layer's thickness for the PE coatings of $80-130 \mu \mathrm{m}$ has no remarkable effect on the main properties of the PE coatings.

Main functional properties of the coatings' inner layer

The average values of the outer layer's adhesion to the inner one for the PE coatings with the average thicknesses of $80 ; 130 \mu \mathrm{m}$, synthesized on AA2024 alloy under the current densities of 15;30; $45 \mathrm{~A} / \mathrm{dm}^{2}$, are low (do not exceed 10; 9; $7 \mathrm{MPa}$, respectively) and do not depend on a coating's thickness. The low adhesion between the layers is probably caused by 
the melting and compacting of the inner layer's regions, which results in its local peeling from the outer one.

The average adhesion values of the inner layer to the metal substrate are considerably high. This adhesion depends on the PE coatings' thickness but not on values of the applied alternating current densities. Thus, the adhesions of the PE coatings with the average thickness of the inner layer of $50 \mu \mathrm{m}$, synthesized under the current density of $15 ; 30 ; 45$ $\mathrm{A} / \mathrm{dm}^{2}$, are $38.5 \pm 5.5 ; 37.0 \pm 6.5 ; 39.0 \pm 6.5 \mathrm{MPa}$, respectively.

Microhardness of the coatings' inner layer $(1840 \pm 14 \mathrm{HV})$, which has the average thickness in the range of 50-70 $\mu \mathrm{m}$, is almost not affected by the coatings' thickness and the values of the current density, applied for the PET processing of AA2024 alloy. The high microhardness is, probably, caused by a high content (up to $30 \mathrm{wt} \%$ [8-10]) of the aluminum oxide high-temperature modification $\left(\alpha-\mathrm{Al}_{2} \mathrm{O}_{3}\right)$ in composite coatings, which mainly consist of $\gamma-\mathrm{Al}_{2} \mathrm{O}_{3}$. The obtained average values of the inner layer's microhardness indicate that they also have good wear resistance properties [9]. It should be noted that the thicker inner layer of the PE coatings provides longer lasting performance in friction conditions.

Anticorrosion properties of the coatings' inner layer are very high. After $480 \mathrm{~h}$ exposure of the PE treated AA2024 alloy (an average thickness of the inner layer is in the range of 50-70 $\mu \mathrm{m}$ ) in the salt spray chamber according to GOST 9.308-85 (Part 1), no pits were found on the samples' surface.

Moreover, the high anticorrosive properties of the coatings' inner layer were proved by the additional electrochemical measurements. The values of anodic and cathodic currents, obtained for the PE coated AA2024 alloy are considerably lower than the ones measured for AA2024 alloy with a passive layer on it (Figure 7).
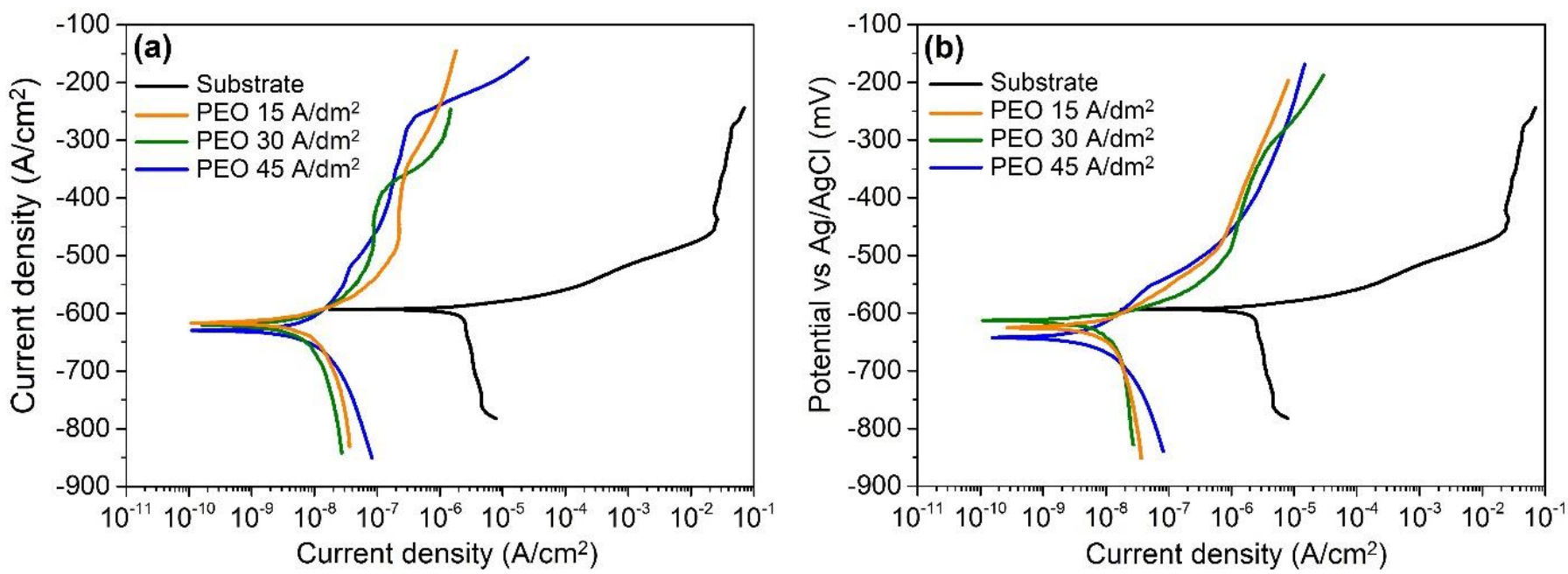

Figure 7. Potentiodynamic polarization curves for the corrosion of AA2024 alloy in a 3 wt\% $\mathrm{NaCl}$ solution without and with the PE coatings: average thicknesses of the coatings' inner layer are ca. 50 (a), 70 (b) $\mu \mathrm{m}$. 


\section{Conclusions}

1. A mechanism of the coatings' formation during the PET of AA2024 alloy under various applied current densities with different time processing in the alkali electrolyte with a small content of TWG was developed and proposed. The mechanism can be divided into four main stages of the coatings' growth for all the applied alternating current densities.

2. It was established that the formation of the coatings' outer layer mainly occurs via a mechanism of the transportation of the melted aluminum oxide onto the coatings' surface with the simultaneous influence of a gas-vapor phase, which appear suddenly after the ignition of microdischarges in the coatings' transverse pores, on it. In most cases, it takes place when the anodic voltage reaches its peak value.

3. It was found that the growth of the coatings' inner layer, in most cases, occurs via two mechanisms. The first mechanism takes place during the second and third stages of the process when microdischarges appear before the anodic voltage reaches its maximum value, thus, the formation of the melted aluminum oxides exists. It seals pores of the coatings' inner layer and the adjacent ones that are located in the outer layer. The second mechanism generally takes place during the second, third and fourth stages and represents the convective and diffusive transfer of aluminum and oxygen ions through the melted parts of the coatings' inner layers which are adjacent to the powerful microdischarges.

4. It was shown that a main reason for the high ratio of the inner layer's thickness to the outer one ( 2.5) at the end of the third stage is caused by the consumption of aluminum not only for the PE coatings' growth but also for the filling of the voids, transverse pores, particularly, the ones located in the inner layer.

5. It was established that the significant raise of the current density, which is applied to conduct PET of AA2024 alloy, only results in the increase of the coatings' thickness' growth rate. It does not influence: (i) the coatings' thickness' intervals, when the mechanisms of the inner and outer layers' growth differ; (ii) the coatings' anticorrosion properties; (iii) the values of the inner layers' microhardness and their adhesion to the metal substrate.

6. It was shown that in order to obtain the hard anticorrosive inner layer of the PE coating it is enough to conduct the PET of AA2024 alloy under the applied current densities of 15$45 \mathrm{~A} / \mathrm{dm}^{2}$ till the completion of the third stage. It should be noted that the average thickness of these coatings is approximately $80 \mu \mathrm{m}$.

\section{Acknowledgements}

This research was funded by the Russian Science Foundation, grant number 21-79-30058. It was performed using the equipment of the Centre for collective use "State Engineering Center" of MSUT "STANKIN" supported by the Ministry of Higher Education of the Russian Federation (project 075-15-2021-695). 


\section{References}

1. P.G. Sheasby and R. Pinner, The Surface Treatment and Finishing of Aluminum and its Alloys, 6th ed., vol. 1, ASM International, 2001, p. 1387.

2. N.D. Tomashov and G.P. Chernova, Theory of Corrosion and Corrosion-Resistant Structural Alloys, Moscow, Metallurgiya, 1993, p. 416 (in Russian).

3. V.S. Sinyavsky, V.D. Valkov and V.D. Kalinin, Corrosion and Protection of Aluminum Alloys, Moscow, Metallurgiya, 1979, p. 224 (in Russian).

4. A.C. Bouali, M. Serdechnova, C. Blawert, J. Tedim and M.G.S. Ferreira, Layered double hydroxides (LDHs) as functional materials for the corrosion protection of aluminum alloys: A review, Appl. Mater. Today, 2020, 21, 100857. doi: 10.1016/j.apmt.2020.100857

5. P. Visser, Y. Liu, H. Terryn and J.M.C. Mol, Lithium salts as leachable corrosion inhibitors and potential replacement for hexavalent chromium in organic coatings for the protection of aluminum alloys, J. Coat. Technol. Res., 2016, 13, 557-566. doi: 10.1007/11998-016-9784-6

6. M.P. Martinez-Viademonte, Sh.T. Abrahami, T. Hack, M. Burchardt and H. Terryn, A review on anodizing of aerospace aluminum alloys for corrosion protection, Coatings, 2020, 10, no. 11, 1106. doi: $10.3390 /$ coatings 10111106

7. E.E. Averyanov, Handbook of Anodizing, Moscow, Mashinostroenie, 1988, p. 224 (in Russian).

8. A.G. Rakoch, A.V. Dub and A.A. Gladkova, Anodizing of light alloys in various electric modes. Plasma-electrolytic nanotechnology, Moscow, Staraya Basmannaya Publishing, 2012, p. 495 (in Russian).

9. A.G. Rakoch, A.A. Gladkova and A.V. Dub, Plasma-electrolytic treatment of aluminum and titanium alloys, Moscow, MISiS Publishing House, 2017, p. 160 (in Russian).

10. I.V. Suminov, A.V. Epelfeld, V.B. Ludin, B.L. Krit and A.M. Borisov, Microarc oxidizing: theory, technology, equipment, Moscow, Ekomet Publ., 2005, p. 368 (in Russian).

11. L.S. Saakian, A.P. Yefremov, L.Y. Ropyak and A.V. Epelfeld, (Application of surface hardening of aluminum alloys and coatings for corrosion and mechanical resistance improvement of oilfield equipment parts, Moscow, VNIIOENG, 1986, p. 60 (in Russian).

12. E.K. Tillous, T. Toll-Duchanoy and E. Bauer-Grosse, Microstructure and 3D microtomographic characterization of porosity of MAO surface layers formed on aluminium and 2214-T6 alloy, Surf. Coat. Technol., 2009, 203, 1850-1855. doi: 10.1016/j.surfcoat.2009.01.014

13. X. Nie, E.I. Meletis, J.C. Jiang, A. Leyland, A.L. Yerokhin and A. Matthews, Abrasive wear/corrosion properties and TEM analysis of $\mathrm{Al}_{2} \mathrm{O}_{3}$ coatings fabricated using plasma electrolysis, Surf. Coat. Technol., 2002, 149, 245-251. doi: 10.1016/S0257$\underline{\text { 8972(01)01453-0 }}$ 
14. V.N. Malyshev, G.A. Markov, V.A. Fedorov, A.A. Petrosyants and O.P. Terleeva, Features of the structure and properties of coatings applied by the method of microarc oxidation, Chem. Pet. Eng., 1984, 20, 41-43. doi: 10.1007/BF01154982

15. G.A. Markov, M.K. Mironova, O.G. Potapova and V.V. Tatarchuk, The structure of anode films during microarc oxidation of aluminum, Izv. Sib. Otd. Akad. Nauk SSSR, Neorg. Mater., 1983, 19, 1110-1113 (in Russian).

16. A.I. Sonova and O.P. Terleeva, Morphology, structure, and phase composition of microplasma coatings formed on Al-Cu-Mg alloy, Prot. Met., 2008, 44, 65-75. doi: 10.1134/S0033173208010098

17. Q.B. Li, C.C. Liu, W.B. Yang and J. Liang, Growth mechanism and adhesion of PEO coatings on 2024Al alloy, Surf. Eng., 2017, 33, no. 10, 760-766. doi: $10.1080 / 02670844.2016 .1200860$

18. G.A. Markov, A.I. Slonova and O.P. Terleeva, Stages of anodic-cathodic microplasma processes, Elektrokhimiya (Electrochemistry), 1989, 25, 1473-1479 (in Russian).

19. A.G. Rakoch, V.V. Khokhlov, V.A. Bautin, N.A. Lebedeva, Yu.V. Magurova and I.V. Bardin, Model concepts on the mechanism of microarc oxidation of metal materials and the control over this process, Prot. Met., 2006, 42, 158-169. doi: 10.1134/S003317320602010X

20. A.G. Rakoch, Yu.I. Kuznetsov, Tran Van Tuan, Z.V. Khabibullina, A.A. Gladkova, A.A. Chirkunov and A.M. Semiletov, Black decorative anticorrosion coatings obtained on AA2024 alloy by plasma-electrolytic treatment and inhibition, Int. J. Corros. Scale Inhib., 2021, 10, no. 2, 562-579. doi: 10.17675/2305-6894-2021-10-2-5

21. Y.J. Guan, Y. Xia and G. Li, Growth mechanism and corrosion behavior of ceramic coatings on aluminum produced by autocontrol AC pulse PEO, Surf. Coat. Technol., 2008, 202, 4602-4612. doi: 10.1016/j.surfcoat.2008.03.031

22. D.D. Wang, X.T. Liu, Y.K. Wang, H.P. Han, Z. Yang, Y. Su, X.Z. Zhang, G.R. Wu and D.J. Shen, Evolution process of the plasma electrolytic oxidation (PEO) coating formed on aluminum in an alkaline sodium hexametaphosphate $\left(\left(\mathrm{NaPO}_{3}\right)_{6}\right)$ electrolyte, J. Alloys Compd., 2019, 798, 129-143. doi: 10.1016/j.jallcom.2019.05.253

23. E. Erfanifar, M. Aliofkhazraei, H.F. Nabavi, H. Sharifi and A.S. Rouhaghdam, Growth kinetics and morphology of plasma electrolytic oxidation coating on aluminum, Mater. Chem. Phys., 2017, 185, 162-175. doi: 10.1016/j.matchemphys.2016.10.019

24. A.G. Rakoch, A.A. Gladkova, L. Zayar and D.M. Strekalina, The evidence of cathodic micro-discharges during plasma electrolytic oxidation of light metallic alloys and microdischarge intensity depending on $\mathrm{pH}$ of the electrolyte, Surf. Coat. Technol., 2015, 269, 138-144. doi: 10.1016/j.surfcoat.2015.02.026

25. A.G. Rakoch, I.V. Bardin, V.L. Kovalev and T.G. Avanesyan, Microarc oxidation of light constructional alloys: Part 1. Main notions on the microarc oxidation of light constructional alloys, Russ. J. Non-Ferrous Met., 2013, 54, 341-344. doi: $\underline{10.3103 / \mathrm{S} 1067821213040135}$ 
26. L.L. Gruss and W. McNeill, Anodic spark reaction products in aluminate, tungstate and silicate solutions, Electrochem. Technol., 1963, 1, 283-287.

27. W. McNeill and L.L. Gruss, Anodic film growth by anion deposition in aluminate, tungstate and phosphate solutions, J. Electrochem. Soc., 1963, 110, no. 8, 853-855. doi: $\underline{10.1149 / 1.2425890}$

28. W. McNeill and L.L. Gruss, Anodic spark reaction process and articles, US Patent 3293158, 1966.

29. G.A. Markov and G.V. Markova, Method for forming anodes of electrolytic capacitors, USSR Patent 526961, 1976 (in Russian).

30. A.V. Nikolaev, G.A. Markov and B.I. Peshchevitskii, A new phenomenon in electrolysis, Izv. Sib. Otd. Akad. Nauk SSSR, Ser. Khim. Nauk, 1977, 5, 32-33 (in Russian).

31. A. Güntherschulze, Electric rectifiers and valves, Moscow, Gosenergoizdat, 1932, p. 272 (in Russian).

32. A. Güntherschulze and H. Betz, Electrolytic rectifying action, Z. Phys., 1932, 78, 196210.

33. A. Güntherschulze and H. Betz, Electrolytic Capacitors, Moscow, Oborongiz, 1938, p. 200 (in Russian).

34. R. Hradcovsky and O. Kozak, Electrolytic production of glassy layers on metals, US Patent 3834999, 1974.

35. R.A. Crawford and H.H. Hoekje, Silica gels and their formation by electrolysis of silicate solutions, US Patent 4193851, 1980.

36. G. Sundararajan and L.R. Krishna, Mechanisms underlying the formation of thick alumina coatings technology, Surf. Coat. Technol., 2003, 167, 269-277. doi: $\underline{10.1016 / \mathrm{S} 0257-8972(02) 00918-0}$ 